Vol 4 No 1 (2021) 27-37 P-ISSN 2620-295 E-ISSN 2747-0490 DOI: 1047467/elmal.v4i1.520

\title{
Pengaruh Keuangan Inklusif dan Bank Syariah terhadap Konsumsi Nasional Indonesia
}

\author{
Arief Rachman Hakim Rangkuti ${ }^{1}$, Ibdalsyah ${ }^{2}$, Abrista Devi ${ }^{3}$ \\ 1,2,3Universitas Ibn Khaldun \\ ariefrangkuti01@gmail.com¹, buyaibdalsyah@gmail.com², \\ abristasmart@gmail.com³
}

\begin{abstract}
This study aims to determine the effect of financial inclusion and Islamic Banks to national consumption in Indonesia. The Data used in this research is the second data obtained through the official website of the authority of the Islamic financial services banking statistics and data from the Central Statistical Office Data. The method used in this research is the analysis of panel data regression with the aid of Eviews 9 to obtain the processed results complete data concerning the relationship of one variable with the variable that the other. The sample of this study consists of 33 provinces in Indonesia with the time frames 2017-2020. The results of this study is that the variable financial inclusion has influence in a positive and partial to the variable of national consumption with the value of the probability of 0,0000 $<0,05$. While the variables of islamic banks have influence in a positive and partial to the variable of national consumption with the value of the probability of 0,0460 $<0,05$. Then for the regression simultaneously obtain the result that financial inclusion and islamic banks jointly affect the national consumption. For the coefficient of determination of the two independent variables against the national consumption by $91 \%$ while the remaining $9 \%$ is explained or influenced by other variables that are not incorporated into the model of this research.
\end{abstract}

Keywords : Financial Inclusion, Islamic Bank, National Consumption

\begin{abstract}
ABSTRACK
Penelitian ini bertujuan untuk mengetahui pengaruh keuangan inklusif dan bank syariah terhadap konsumsi nasional di Indonesia. Data yang digunakan dalam peneltian ini adalah data sekunder yang diperoleh melalui situs resmi dari otoritas jasa keuangan mengenai statistik perbankan syariah dan data dari badan pusat statistik. Metode yang digunakan dalam penelitian ini adalah analisis regresi data panel dengan bantuan aplikasi Eviews 9 untuk memperoleh hasil olahan data yang lengkap mengenai hubungan variabel satu dengan varibel yang lainnya. Sampel dari penelitian ini terdiri dari 33 provinsi di Indonesia dengan rentang waktu 2017-2020. Hasil penelitian ini adalah bahwa variabel keuangan inklusif memiliki pengaruh secara positif dan parsial terhadap variabel konsumsi nasional dengan hasil nilai probabilitasnya sebesar 0,0000< 0,05 . Sedangkan variabel bank syariah memiliki pengaruh secara positif dan parsial terhadap variabel konsumsi nasional dengan hasil nilai probabilitasnya sebesar 0,0460<0,05. Lalu untuk regresi secara simultan memperoleh hasil bahwa keuangan inklusif dan bank syariah secara bersama-sama mempengaruhi konsumsi nasional. Untuk koefisien determinasi dari dua variabel independet tersebut terhadap konsumsi nasional sebesar 91\% sdangkan sisanya 9\% dijelaskan atau dipengaruhi oleh variabel lain yang tidak dimasukkan kedalam model penelitian ini.
\end{abstract}

Kata Kunci: Keuangan Inklusif, Bank Syariah, Konsumsi Nasional 


\section{Vol 4 No 1 (2021) 27-37 P-ISSN 2620-295 E-ISSN 2747-0490 DOI: 1047467/elmal.v4i1.520}

\section{PENDAHULUAN}

SDGs (Sustainable Development Goals) merupakan aspirasi global yang bermaksud untuk menciptakan kehidupan manusia menjadi lebih baik dalam aspek sosial dan ekonomi serta dapat bersinergi dengan lingkungan. Pada penyusunannya, dapat diartikan bahwa inisiatif global ini tidak dapat menampikkan adanya implementasi di tingkat regional dan nasional. SDGs di tingkat regional dan nasional pun perlu meneguhkan kembali semangat dan nilai SDGs yang inklusif dan partisipatif sebagaimana yang telah direncanakan dalam SDGs tingkat global. Peran negara sangat penting dalam memastikan pelaksanaan SDGs mendasarkan pada pendekatan dan strategi yang merata antara pembangunan ekonomi, inklusi sosial, dan keberlanjutan lingkungan dengan tetap mengedepankan pada karakteristik dan prioritas tiap-tiap negara (Panuluh \& Fitri, 2016). Adapun tiga pilar yang menjadi indikator dalam konsep pengembangan SDGs yaitu, pertama indikator yang melekat pembangunan manusia (Human Development), di antaranya pendidikan, kesehatan, konsumsi, produksi. Indikator kedua yang melekat pada lingkungan kecilnya (Social Economic Development), seperti ketersediaan sarana dan prasarana lingkungan, serta pertumbuhan ekonomi. Sementara itu, pada indikator ketiga melekat pada lingkungan yang lebih besar (Environmental Development), yaitu ketersediaan sumber daya alam dan kualitas lingkungan yang baik (Wahyuningsih, 2018).

Konsumsi adalah suatu kegiatan yang bertujuan untuk menghabiskan daya guna suatu benda, baik yang berupa barang ataupun jasa, untuk memenuhi kebutuhan dan kepuasan secara langsung (Ariani, 2014). Secara garis besar konsumsi rumah tangga dibedakan menjadi dua kelompok pertama kebutuhan pokok (primer) dan yang kedua kebutuhan penunjang (sekunder). Yang tergolong kebutuhan primer adalah sandang, pangan dan perumahan. Sedangkan kebutuhan sekunder meliputi kelompok kebutuhan yang tidak selalu menuntut kebutuhan (Masykur dan Nasir, 2015). Faktor utama yang menentukan konsumsi seorang konsumen atas barang dan jasa yaitu tergantung dari tingkat pendapatan konsumen tersebut. Tingkat pendapatan berpengaruh secara positif, dengan maksud apabila pendapatan konsumen naik, maka pengeluaran konsumsinya juga akan mengalami peningkatan, begitu pula sebaliknya (Bagus, 2018).

Salah satu lembaga yang dapat memenuhi sebuah konsumsi masyarakat yaitu melalui pembiayaan pada bank syariah. Bank syariah merupakan lembaga keuangan yang usaha pokoknya memberikan pembiayaan serta jasa-jasa lainnya dalam lalu lintas pembayaran dan peredaran uang yang dalam pengoperasiannya harus memenuhi dengan prinsip syariat Islam (Diana, 2019). Fungsi serta tujuan bank umum syariah meliputi kemakmuran ekonomi yang meluas, penyerapan tenaga kerja serta tingkat pertumbuhan ekonomi yang optimal, keadilan sosial ekonomi, distribusi pendapatan dan kekayaan yang merata, stabilitas nilai uang, mobilitas dan investasi tabungan yang menjamin adanya pengembalian yang adil dan pelayanan yang efektif (Hastuti, 2016).

Keuangan inklusif pada dasarnya merupakan upaya yang dimana disusun secara bersama yang bertujuan menghilangkan segala bentuk hambatan terhadap akses mayarakat untuk memanfaatkan layanan jasa keuangan dengan biaya terjangkau. Bank Indonesia telah menyampaikan enam pilar yang menjadi acuan pelaksanaan keuangan 


\section{Vol 4 No 1 (2021) 27-37 P-ISSN 2620-295 E-ISSN 2747-0490 DOI: 1047467/elmal.v4i1.520}

inklusif di Indonesia. Ke enam pilar tersebut yaitu: Edukasi Keuangan, Fasilitas Keuangan Publik, Pemetaan informasi keuangan, kebijakan/peraturan pendukung, fasilitas intermediasi \& distribusi, dan perlindungan terhadap konsumen (Nasution dan Dwilita, 2016).

\section{METODOLOGI PENELITIAN}

Jenis penelitian yang digunakan pada penelitian ini adalah kuantitatif asosiatif. Metode penelitian kuantitatif adalah data dalam angka dan lambang matematik atau dengan kata lain dapat diukur dengan skala numerik, oleh karena itu data kuantitatif dapat langsung diolah secara statistik (Tanjung dan Devi, 2018).

Jenis peneliatian assosiatif adalah penelitian yang bersifat menanyakan hubungan antara dua variabel atau lebih. Dalam penelitian asosiatif terdapat tiga bentuk hubungan yang mendasarinya, yaitu hubungan simetris, hubungan kausal, dan hubungan interaktif/resiprokal/timbal balik. Penelitian ini mengacu pada hubungan kausal dimana menunjukkan hubungan yang bersifat sebab akibat dengan menunjukkan adanaya variabel independent (variable yang mempengaruhi atau $\mathrm{X}$ ) dan variabel dependent (dipengaruhi atau Y) (Sugiyono, 2013).

Tujuan penelitian lebih di arahkan untuk menunjukkan hubungan antar variabel, memverifikasi teori, melakukan prediksi, dan generalisasi. Peneliti kuantitatif akan menganalisis fenomena berdasar pada teori yang dimilikinya. Teori-teori yang diajukan dijadikan sebagai standar untuk mengemukakan sesuai tidaknya sebuah gejala yang terjadi, dan disinilah muncul istilah kebenaran etik, sebuah kebenaran berdasarkan pada teori yang diajukan peneliti (Usman dan Abdi, 2008).

Metode yang digunakan pada penelitian ini dengan menggunakan data panel yaitu penggabungan antara data time series dan data cross section dan dengan menggunakan aplikasi Eviews. Data dalam penelitian ini berupa laporan tahunan yang diperoleh melalui situs resmi BPS (Badan Pusat Statistik), dan OJK (Otoritas Jasa Keuangan).

\section{HASIL ANALISIS DAN PEMBAHASAN}

\section{Statistik deskriptif}

Statistik deskriptif adalah suatu analisis statistik yang dimana digunakan untuk melakukan perhitungan hanya sebatas data yang dikumpulkan atau tidak digunakan untuk membuat kesimpulan yang general (Maswar, 2017). Adapun tabel statistik deskriptif pada penelitian ini dapat dilihat pada tabel berikut:

Tabel 1. Statistik Deskriptif

\begin{tabular}{|c|c|c|c|}
\hline \multicolumn{4}{|c|}{\begin{tabular}{|c|} 
Date: \\
07/31/21 \\
Time: $20: 39$ \\
Sample: 20172020
\end{tabular}} \\
\hline & Y & $\mathrm{X} 1$ & $\mathrm{X} 2$ \\
\hline Mean & 13.92795 & 7.907121 & 7.889470 \\
\hline
\end{tabular}


Vol 4 No 1 (2021) 27-37 P-ISSN 2620-295 E-ISSN 2747-0490 DOI: 1047467/elmal.v4i1.520

\begin{tabular}{|lccc|} 
Median & 13.90000 & 7.900000 & 8.245000 \\
Maximum & 14.63000 & 12.78000 & 11.97000 \\
Minimum & 13.43000 & 4.710000 & 4.770000 \\
Std. Dev. & 0.216864 & 1.748091 & 1.659135 \\
Skewness & 0.661603 & 0.398999 & 0.046935 \\
Kurtosis & 3.923464 & 2.723533 & 2.580047 \\
Jarque-Bera & 14.32012 & 3.922789 & 1.018447 \\
Probability & 0.000777 & 0.140662 & 0.600962 \\
Sum & 1838.490 & 1043.740 & 1041.410 \\
Sum Sq. Dev. & 6.160948 & 400.3127 & 360.6075 \\
Observations & 132 & 132 & 132 \\
\hline
\end{tabular}

Dari tabel diatas, dapat diketahui bahwa variabel (X1) keuangan inklusif memiliki nilai rata-rata sebesar 7,907121, nilai maksimum 12,78000 dan nilai minimun 4,710000 serta standar deviasi sebesar 1,748091 dengan jumlah observasi sebanyak 132 .

Variabel (X2) Bank Syariah memiliki nilai rata-rata sebesar 7,889470, nilai maksimum 11,97000 dan nilai minimun 4,770000 serta standar deviasi sebesar 1,659135 dengan jumlah observasi sebanyak 132.

Variabel (Y) Konsumsi memiliki nilai rata-rata sebesar 13,92795, nilai maksimum 14,63000 dan nilai minimun 13,43000 serta standar deviasi sebesar 0,216864 dengan jumlah observasi sebanyak 132.

\section{Pengujian Model}

Pengujian model dalam regresi data panel dapat dilakukan dengan tiga pendekatan metode yaitu common effect model, fixed effect model dan random effect model. Langkah untuk menentukan model yang terbaik antara tiga model persamaan yaitu Common Effect Model (CEM), Fixed Effect Model (FEM) dan Random Effect Model (REM), perlu adanya pengujian pada masing-masing model tersebut dengan menggunakan uji-uji sebagai berikut:

Uji Lagrange Multiplier (Common Effect Model vs Random Effect Model)

Uji lagrange multiplier sebagai uji guna mengetahui metode mana yang lebih cocok untuk digunakan antara common effect model dengan random effect model dengan kriteria sebagai berikut:

1. Jika nilai cross section Breusch -pagan $\geq 0.05$ maka $\mathrm{H}_{0}$ diterima, sehingga dikatakan common effect sebagai model yang paling tepat digunakan.

2. Jika nilai cross section Breusch-pagan $\leq 0.05$ maka $\mathrm{H}_{0}$ ditolak, sehingga dikatakan random effect sebagai model yang paling tepat digunakan. Hipotesis yang digunakan, sebagai berikut: 
Vol 4 No 1 (2021) 27-37 P-ISSN 2620-295 E-ISSN 2747-0490

DOI: 1047467/elmal.v4i1.520

$\mathrm{H}_{0}$ : Common Effect Model (CEM)

$\mathrm{H}_{1}$ : Random Effect Model (REM)

Hasil uji lagrange multiplier terlihat pada table berikut:

Tabel 2. Uji Lagrange Multiplier

\begin{tabular}{|c|c|c|c|}
\hline $\begin{array}{l}\text { Lagrange Multi } \\
\text { Null hypotheses } \\
\text { Alternative hyp } \\
\text { one-sided } \\
\text { (all others) }\end{array}$ & $\begin{array}{l}\text { ests for Ral } \\
\text { ffects } \\
\text { s: Two-sid } \\
\text { atives }\end{array}$ & om Effects & gan) and \\
\hline & & t Hypothe & \\
\hline & $\begin{array}{l}\text { Cross- } \\
\text { section }\end{array}$ & Time & Both \\
\hline Breusch-Pagan & $\begin{array}{l}149.8206 \\
(0.0000)\end{array}$ & $\begin{array}{l}1.747048 \\
(0.1862)\end{array}$ & $\begin{array}{l}151.5676 \\
(0.0000)\end{array}$ \\
\hline
\end{tabular}

Sumber: hasil output data panel Eviews 9

Berdasarkan hasil pada table diatas dari uji lagrange multiplier, common effect model vs random effect model diatas, diperoleh cross section Breusch-pagan $\leq 0.05$ yaitu $0.0000 \leq$ 0.05 maka hipotesis $\mathbf{H}_{\mathbf{0}}$ ditolak dan $\mathbf{H}_{\mathbf{1}}$ diterima yang berarti Random Effect Model (REM) lebih tepat digunakan.

Uji Chow (Common Effect Model vs Fixed Effect Model)

Uji chow digunakan untuk memilih pendekatan yang lebih baik di antara model common effect model dengan fixed effect model dengan kriteria, sebagai berikut:

1. Jika nilai probabilitas $P$-value cross section $\mathrm{F} \geq 0.05$, maka $\mathrm{H}_{0}$ diterima sehingga model yang tepat untuk digunakan adalah Common Effect Model.

2. Jika nilai probabilitas $P$-value cross section $\mathrm{F} \leq 0.05$, maka $\mathrm{H}_{0}$ ditolak sehingga model yang tepat untuk digunakan adalah Fixed Effect Model.

Hipotesis yang digunakan dalam uji chow adalah sebagai berikut :

$\mathrm{H}_{0}$ : Commont Effect Model (CEM)

$\mathrm{H}_{1}$ : Fixed Effect Model (FEM)

Hasil dari uji chow dapat dilihat dalam table 4 sebagai berikut:

Tabel 3. Uji Chow

\begin{tabular}{|c|c|c|c|}
\hline $\begin{array}{l}\text { Redundant Fixed Effects T } \\
\text { Equation: FEM } \\
\text { Test cross-section fixed ef }\end{array}$ & & & \\
\hline Effects Test & Statistic & d.f. & Prob. \\
\hline Cross-section F & $\begin{array}{l}35.470720 \\
335.50893\end{array}$ & $(32,97)$ & 0.0000 \\
\hline Cross-section Chi-square & 3 & 32 & 0.0000 \\
\hline
\end{tabular}


Vol 4 No 1 (2021) 27-37 P-ISSN 2620-295 E-ISSN 2747-0490 DOI: $1047467 /$ elmal.v4i1.520

Sumber: hasil output data panel Eviews 9

Berdasarkan table diatas pada hasil uji chow, common effect model vs fixed effect model diatas, diperoleh nilai probabilitas ( $P$-value) cross section F sebesar $0.0000 \leq 0.05$ maka hipotesis $\mathbf{H}_{\mathbf{0}}$ ditolak dan $\mathbf{H}_{\mathbf{1}}$ diterima yang berarti model Fixed Effect Model (FEM) merupakan model yang lebih tepat untuk digunakan.

Uji Hausman (Random Effect Model vs Fixed Effect Model)

Uji hausman merupakan pengujian untuk membandingkan antara random effect model dengan fixed effect model. Hasil pengujian ini untuk mengetahui metode mana yang sebaiknya dipilih dengan kriteria sebagai berikut:

1. Jika nilai probabilitas chi-square $\geq 0.05$ maka $\mathrm{H}_{0}$ diterima, sehingga model yang tepat untuk digunakan adalah random effect model (REM).

2. Jika nilai probabilitas chi-square $\leq 0.05$ maka $\mathrm{H}_{0}$ ditolak, sehingga model yang tepat untuk digunakan adalah fixed effect model (FEM).

Hipotesis yang digunakan dalam uji hausman adalah sebagai berikut:

$\mathrm{H}_{0}:$ Random Effect Model (REM)

$\mathrm{H}_{1}:$ Fixed Effect Model (FEM)

Hasil uji hausman dapat dilihat pada tabel 4 sebagai berikut:

Tabel 4. Uji Hausman

Correlated Random Effects - Hausman Test

Equation: REM

Test cross-section random effects

\begin{tabular}{|lrrr|}
\hline \hline Test Summary & $\begin{array}{c}\text { Chi-Sq. } \\
\text { Statistic }\end{array}$ & Chi-Sq. d.f. & Prob. \\
\hline \hline Cross-section random & 16.777974 & 2 & 0.0002 \\
\hline \hline
\end{tabular}

Sumber: hasil output data panel Eviews 9

Berdasarkan tabel diatas pada hasil uji hausman, random effect model vs fixed effect model diatas, diperoleh nilai probabilitas chi-square sebesar $0.0002 \leq 0.05$ maka hipotesis $\mathbf{H}_{\mathbf{0}}$ ditolak dan $\mathbf{H}_{\mathbf{1}}$ diterima yang berarti model Fixed Effect Model (FEM) merupakan model yang lebih tepat untuk digunakan.

Dari hasil diatas dapat ditarik kesimpulan bahwa model yang paling cocok untuk digunakan dalam penelitian ini yaitu dengan menggunakan model Fixed Effect Model (FEM).

Tabel 5. Uji Pemilihan Metode Regresi Data Panel 
Vol 4 No 1 (2021) 27-37 P-ISSN 2620-295 E-ISSN 2747-0490 DOI: 1047467/elmal.v4i1.520

\begin{tabular}{|c|l|c|c|c|}
\hline No & \multicolumn{1}{|c|}{ Test } & $\begin{array}{c}\text { Commont } \\
\text { Effect model }\end{array}$ & $\begin{array}{c}\text { fixed Effect } \\
\text { model }\end{array}$ & $\begin{array}{c}\text { Random Effect } \\
\text { model }\end{array}$ \\
\hline 1 & Uji Chow & & $\mathrm{x}$ & \\
\hline 2 & Uji Hausman & & $\mathrm{x}$ & \\
\hline 3 & $\begin{array}{l}\text { Uji Lagrange } \\
\text { Multiplier }\end{array}$ & & & $\mathrm{x}$ \\
\hline \multicolumn{2}{l}{ Kesimpulan } & & $\mathrm{x}$ & \\
\hline
\end{tabular}

Setelah melakukan pengujian pemilihan model regresi data panel, langkah selanjutnya adalah melakukan uji asumsi klasik.

\section{Asumsi Klasik}

a. Uji autokolerasi

Uji autokorelasi adalah hubunngan antara anggota seri dari observasiobservasi yang diurutkan berdasarkan waktu (data time series) atau tempat (data cross section). Model regresi yang baik adalah regresi yang bebas dari autokorelasi. Salah satu uji yang dapat digunakan untuk mendeteksi adanya autokorelasi adalah dengan uji BreuschGodfrey, yaitu apabila nilai dari probabilitas $>0,05$ berarti tidak terjadi autokorelasi. Sebaliknya nilai probabilitas $<0,05$ berarti terjadi autokorelasi. Berikut hasil dari uji autokolerasi yang dapat dilihat pada tabel 6:

\section{Tabel 6. Uji autokolerasi}

\begin{tabular}{|lrlr|}
\hline \multicolumn{4}{|l|}{ Breusch-Godfrey Serial Correlation LM Test: } \\
\hline \hline F-statistic & 2.666808 & Prob. F(2,126) & 0.0734 \\
Obs*R-squared & 5.320068 & Prob. Chi-Square(2) & 0.0699 \\
\hline
\end{tabular}

Sumber: hasil output data panel Eviews 9

Berdasarkan tabel diatas dapat dilihat nilai prob.chi-square sebesar 0,0699 > 0.05, maka dapat disimpulkan bahwa tidak terjadi masalah autokorelasi.

\section{b. Uji Heteroskedastisitas}

Uji heteroskedastisitas dalam penelitian ini menggunakan uji Harvey. Hasil yang diperlukan dari uji ini untuk variabel dependent adalah nilai prob.chi-square (yang Obs* $R$ Squared) harus lebih besar dari 0,05 $(>0,05)$. Berikut hasil dari uji heteroskedastisitas yang dapat dilihat pada tabel 7 :

Tabel 7. Uji Heteroskedastisitas

\begin{tabular}{|lrll|}
\hline \multicolumn{3}{|l|}{ Heteroskedasticity Test: Harvey } & \\
\hline \hline F-statistic & 1.207545 & Prob. F(2,129) & 0.3023 \\
Obs*R-squared & 2.425839 & Prob. Chi-Square(2) & 0.2973 \\
Scaled explained SS & 2.957147 & Prob. Chi-Square(2) & 0.2280 \\
\hline \hline
\end{tabular}

Sumber: hasil output data panel Eviews 9 


\section{Vol 4 No 1 (2021) 27-37 P-ISSN 2620-295 E-ISSN 2747-0490 DOI: $1047467 /$ elmal.v4i1.520}

Berdasarkan hasil uji heteroskedastisitas diatas terlihat nilai prob.chi-square (yang $O b s^{*} R$ Squared) sebesar 0,2973 > 0,05, sehingga dapat disimpulkan bahwa tidak terjadi heteroskedastisitas pada penelitian ini.

\section{Pengujian Hipotesis dengan Regresi Data Panel}

a. Pengaruh Inklusi Keuangan dan Bank Syariah terhadap Konsumsi Nasional secara Parsial (uji-t).

Untuk melihat ada atau tidaknya pengaruh dari variabel secara parsial terhadap konsumsi nasional maka harus dilakukan uji-t. Uji-t digunakan untuk melihat pengaruh variabel independent terhadap variabel dependentnya. Apabila nilai probabilitas $\mathrm{t}<0,05$ maka hasilnya signifikan berarti ada pengaruh dari variabel independent terhadap variabel dependent. Hasil uji-t dapat dilihat pada tabal 8 sebagai berikut:

Tabel 8. Uji-t

\begin{tabular}{|c|c|c|c|c|}
\hline & Coefficien & & & \\
\hline Variable & $\mathrm{t}$ & Std. Error & t-Statistic & Prob. \\
\hline $\mathrm{C}$ & 12.36401 & 0.253565 & 48.76068 & 0.0000 \\
\hline $\mathrm{X} 1$ & 0.125587 & 0.023608 & 5.319684 & 0.0000 \\
\hline $\mathrm{X} 2$ & 0.072364 & 0.035932 & 2.013901 & 0.0468 \\
\hline
\end{tabular}

Sumber: hasil output data panel Eviews 9

b. Pengaruh Inklusi Keuangan dan Bank Syariah terhadap Konsumsi Nasional secara Simultan (uji-f).

Uji-f digunakan untuk mengetahui ada atau tidaknya pengaruh variabel secara bersama-sama (simultan) terhadap konsumsi nasional maka dilakukan uji-f. Apabila nilai probabilitas f (statistic) $<0,05$ maka hasilnya memiliki pengaruh yang signifikan terhadap variabel dependent.

Hasil uji-f dapat dilihat sebagai berikut:

Tabel 9. Uji-f

\begin{tabular}{|lllr|}
\hline \multicolumn{2}{|l|}{ Cross-section fixed (dummy variables) } \\
\hline \hline \\
R-squared & 0.934915 & Mean dependent var & 13.9279 \\
Adjusted R- & & & 5 \\
squared & 0.912101 & S.D. dependent var & 0.21686 \\
& & & 4 \\
& & & - \\
S.E. of regression & 0.064295 & Akaike info criterion & 2.42844 \\
& & & 6 \\
& & & 1.66406 \\
Sum squared resid & 0.400988 & Schwarz criterion & 6
\end{tabular}


Vol 4 No 1 (2021) 27-37 P-ISSN 2620-295 E-ISSN 2747-0490 DOI: 1047467/elmal.v4i1.520

\begin{tabular}{|lrrr|} 
& \multicolumn{2}{c}{ Hannan-Quinn } & -11783 \\
Log likelihood & 195.2774 criter. & 7 \\
& & & 2.09868 \\
F-statistic & 40.98084 & Durbin-Watson stat & 7 \\
Prob(F-statistic) & 0.000000 & \\
\hline \hline
\end{tabular}

Sumber: hasil output data panel Eviews 9

\section{c. Koefisien Determinasi (Adjusted R-Squared)}

Koefisien determinasi $\left(\mathrm{R}^{2}\right)$ digunakan untuk mengetahui presentase variabel independent secara bersama-sama dapat menjelaskan variabel dependent. Nilai koefisien determinasi adalah diantara nol dan satu. Jika koefisien determinasi $\left(\mathrm{R}^{2}\right)=1$, artinya variabel independent memberikan informasi yang dibutuhkan untuk mempredisikan variabel-variabel dependent. Jika koefisien determinasi $\left(\mathrm{R}^{2}\right)=0$, artinya variabel independent tidak mampu menjelaskan pengaruhnya terhadap variabel dependent.

Tabel 10. Koefisien Determinasi

\begin{tabular}{|lcrr|}
\hline Cross-section fixed (dummy variables) & \\
\hline \hline & & & 13.9279 \\
R-squared & 0.934915 & Mean dependent var & 5 \\
Adjusted R- & & & 0.21686 \\
squared & 0.912101 & S.D. dependent var & 4 \\
& & & - \\
& & & 2.42844 \\
S.E. of regression & 0.064295 & Akaike info criterion & 6 \\
& & & - \\
& & & 1.66406 \\
Sum squared resid & 0.400988 & Schwarz criterion & 6 \\
& & & - \\
& & Hannan-Quinn & 2.11783 \\
Log likelihood & 195.2774 criter. & 7 \\
& & & 7 \\
F-statistic & 40.98084 & Durbin-Watson stat & \\
Prob(F-statistic) & 0.000000 & & \\
\hline \hline
\end{tabular}

Sumber: hasil output data panel Eviews 9

\section{Pembahasan Hasil Penelitian}

Analisis regresi yang telah dilaksanakan bertujuan untuk mengetahui hubungan yang dapat diukur dari Inklusi Keuangan (X1), Bank Syariah (X2) terhadap Konsumsi Nasional (Y). Berikut ini adalah tabel yang merangkum hubungan antara variabel independent dengan variabel dependent secara parsial. 
Vol 4 No 1 (2021) 27-37 P-ISSN 2620-295 E-ISSN 2747-0490

DOI: 1047467/elmal.v4i1.520

Tabel 11. Pembahasan Hasil Penelitian

\begin{tabular}{|c|c|c|c|c|c|}
\hline \multirow{2}{*}{$\begin{array}{c}\text { Konsumsi } \\
\text { (Y) }\end{array}$} & \multicolumn{2}{|c|}{ Keunagan Inklusif (X1) } & \multicolumn{2}{c|}{ Bank Syariah (X2) } & \multirow{2}{*}{ Adj R 2} \\
\cline { 2 - 5 } & Coefficient & Probability & Coefficient & Probability & \\
\cline { 2 - 5 } & {$[* *] 0.125587$} & Signifikan & {$\left[^{* *}\right] 0.072364$} & Signifikan & 0,912101 \\
\hline
\end{tabular}

*Significant $10 \%$

** Significant $5 \%$

*** Significant $1 \%$

\section{KESIMPULAN}

Berdasarkan hasil penelitian tentang pengaruh keuangan inklusif dan bank syariah terhadap konsumsi nasional di Indonesia, maka dapat ditarik kesimpulan diantaranya:

Dimana keuangan inklusif ternyata memiliki pengaruh terhadap konsumsi nasional secara siginifikan dan positif. Sebagaimana hasil Hasil uji-t pada variabel keuangan inklusif terhadap konsumsi nasional terlihat nilai probabilitasnya sebesar $0,0000<0,05$, sehingga dapat disimpulkan bahwa variabel keuangan inklusif memiliki pengaruh terhadap konsumsi nasional.

Dimana bank syariah ternyata memiliki pengaruh terhadap konsumsi nasional secara signifikan dan positif. Sebagaimana hasil uji-t pada variabel bank syariah terhadap konsumsi nasional terlihat nilai probabilitasnya sebesar $0,046<0,05$, sehingga dapat disimpulkan bahwa variabel bank syariah memiliki pengaruh terhadap konsumsi nasional.

Nilai Adjusted R-squared sebesar 0,91 (91\%) mengandung arti bahwa variasi Y dapat dijelaskan oleh X1 dan X2 sebesar 91\%, sedangkan sisanya (100\%-91\%=9\%) dijelaskan oleh variabel lain diluar model.

\section{DAFTAR PUSTAKA}

Ariani, D. (2014). Analisis Faktor-Faktor Yang Mempengaruhi Konsumsi di Kabupaten Nagan Raya. Jurnal Ekonomi dan Kebijakan Publik Indonesia, 1(1), 1-7.

Bagus Eryanto, M. (2018). Analisis Faktor-Faktor Yang Mempengaruhi Konsumsi Masyarakat Di Indonesia Tahun 2009. I-2017. III (Doctoral dissertation, Universitas Muhammadiyah Surakarta).

DIANA, D. (2019). Pengaruh Pembiayaan Mudharabah, Musyarakah, Murabahah, dan Ijarah Terhadap ROA Dengan BOPO dan NPF Sebagai Variabel Moderasi pada Bank Umum Syariah Periode 2014-2018 (Doctoral dissertation, IAIN SALATIGA). 


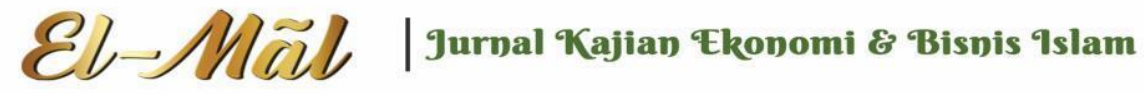

\section{Vol 4 No 1 (2021) 27-37 P-ISSN 2620-295 E-ISSN 2747-0490 DOI: 1047467/elmal.v4i1.520}

Hastuti, L. (2016). analisis pengaruh dana pihak ketiga, non performing financing, financing to deposit rasio terhadap volume pembiayaan pada bank umum syariah di indonesia periode 2011-2014 (Doctoral dissertation, Universitas Muhammadiyah Surakarta).

Maswar, M. (2017). Analisis Statistik Deskriptif Nilai UAS Ekonomitrika Mahasiswa dengan Program SPSS 23 \& Eviews 8.1. Jurnal Pendidikan Islam Indonesia, 1(2), 273-292.

Masykur, M. N. S., \& Nasir, M. (2015). ANALISIS FAKTOR-FAKTOR YANG MEMPENGARUHI PENGELUARAN KONSUMSI RUMAH TANGGA MISKIN DI

KABUPATEN ACEH BARAT. Jurnal Ilmu Ekonomi: Program Pascasarjana Unsyiah, 3(3).

Nasution, L. N., \& Dwilita, H. (2016). Kewangan Inklusif dan Pertumbuhan Ekonomi SUMUT. Jurnal Ilmiah Research Sains, 2.

Panuluh, S., \& Fitri, M. R. (2016). Perkembangan Pelaksanaan Sustainable Development Goals (SDGs) di Indonesia. Biefing Paper, 2, 1-25.

Sugiyono, S. (2010). Metode penelitian kuantitatif dan kualitatif dan R\&D. Alfabeta Bandung.

Usman Rianse, A., \& Abdi, S. P. (2008). Metodologi Penelitian Sosial Dan Ekonomi: Teori Dan Aplikasi. Bandung: Alfabeta.

Wahyuningsih, W. (2018). Millenium Develompent Goals (Mdgs) Dan Sustainable Development Goals (Sdgs) Dalam Kesejahteraan Sosial. BISMA: Jurnal Bisnis dan Manajemen, 11(3), 390-399. 